\title{
種々の置換とーラクトンとビニルマグネ シウムクロリドの反応
}

\author{
藤田 力*・須賀恭一*・渡辺昭次* \\ 川田修*.栗原浩 之*
}

The Reaction of Various Substituted $r$-Lactones with Vinylmagnesium Chloride

Tsutomu Fujit A*, Kyoichi SugA*, Shoji Watanabe*, Osamu KawAt A* and Hiroyuki Kurihara*

The reaction of various $\gamma$-lactones with vinylmagnesium chloride was carried out. From 2,2,4-trimethyl$r$-butyrolactone (1), a mixture of 8-hydroxy-6,6-dimethyl-1-nonen-5-one (2) (yield, 42.5\%) and 4,4dimethylyl-5-vinyl-6-heptene-2,5-diol (3) (yield, 18.8\%) was obtained. However, in the presence of copper ( I ) chloride, the yield of (3) was supressed and 8-hydroxy-6, 6-dimethyl-1-nonen-5-one (2) (yield, 42\%) was obtained almost exclusively.

\section{1. 緒言}

特殊なグリニャール試薬であるビニルマグネシウムク ロリドと種々の化合物との反応は広く検討されてお $\eta^{1,2)}$ 著者らも前報でビニルマグネシウムクロリドと $\beta-$ ヒドロキシ酸エステルの反応を報告した3)。しかし，r ラクトンと普通のグリニャール試薬の反応についてはメ チルマグネシウムブロミドと 4 -ペンチルーr-ブチロラク トンとの反応から 2-メチル-2, 5-デカンジオールが 57\% の収率で得られるといら報告")のほかには, 詳細な検討 は試みられていないようである。今回著者らは今までに 報告されていない種々の置換 $\boldsymbol{\gamma}$-ラクトンとビニルマグ ネシウムクロリドとの反応を試み, 興味ある結果が得ら れたのでここに報告する。

\section{2. 結果と考察}

2,2,4-トリメチルーr-ブチロラクトン (1) とビニルマ グネシウムクロリドとの反応からは 8-ヒドロキシー6, 6-

* 千葉大学工学部工業化学科(

* Department of Applied Chemistry, Faculty of Engineering,
ジメチル-1-ノネン-5-オン (2) (収率 43\%) と 4, 4-ジ メチル-5-ビニル-6-ヘプテン-2,5-ジオール (3) (収率 19\%）の混合物が得られた。同様に種々の r-ラクトン とビニルマグネシウムクロリドと反応を試み 表 1, 表 2 に示す結果を得た。表 1 , 表 2 から明らかなように ラクトンの $\propto$-位の置換基が大きくなるにつれて, ビニ ルマグネシウムクロリドが 2 分子付加した型のケトン体 の割合が増加する傾向にある。しかし， $\beta$ ーヒドロキシ酸 エステルとビニルマグネシウムクロリドとの反応で生じ た分解生成物は全く得られなかった。<smiles>CC1CC(C)(C)C(=O)O1</smiles>

(1)<smiles>C=CCCC(=O)C(C)(C)CC(C)O</smiles>

( 2 )<smiles>C=CC(C)(O)C(C)(C=C)CC(C)O</smiles>

(3)

また著者らは塩化銅（I）の存在下でカルボン酸エス テルとビニルマグネシウムクロリドとの反応から 1,6ジケトンが得られることを報告しており ${ }^{5)}$ ，本反応に関 しても塩化銅（I）の存在下で試みた。すなおち，r-ラ 
クトン (1) とビニルマグネシウムクロリドを塩化銅存在 下で行なったところ, ジオール（3）は全く得られずケト ン体 (2) のみが収率 $40 \%$ で得られた。同様に種々の rーラクトンとビニルマグネシウムクロリドとの反応を塩 化銅（I）の存在下で行ない表 3 に示す結果を得た。 $r$ ラクトンの $\alpha$ 位の置換基の大きさに関係なく,$r$-ラク トンにビニルマグネシウムクロリドが 2 分子付加したケ トン体が主生成物として得られた。

Table 1 Reaction of $\gamma$-Lactones with Vinylmagnesium Chloride

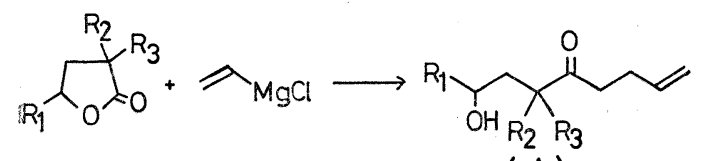

(A)

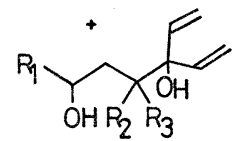

(B)

\begin{tabular}{|c|c|c|c|c|c|}
\hline \multicolumn{3}{|c|}{$\gamma$-Lactones } & \multirow{2}{*}{\multicolumn{2}{|c|}{$\begin{array}{l}\text { Products } \\
\text { (A) (B) } \\
\text { (yield, \%) }\end{array}$}} & \multirow{2}{*}{$(A):(B)$} \\
\hline $\mathrm{R}_{1}$ & $\mathrm{R}_{2}$ & $\mathrm{R}_{3}$ & & & \\
\hline $\mathrm{CH}_{3}$ & $\mathrm{H}$ & $\mathrm{H}$ & 0 & 60 & $0: 100$ \\
\hline $\mathrm{CH}_{3}$ & $\mathrm{CH}_{3}$ & $\mathrm{H}$ & 11 & 63 & $15: 85$ \\
\hline $\mathrm{CH}_{3}$ & $\mathrm{C}_{2} \mathrm{H}_{5}$ & $\mathrm{H}$ & 9 & 23 & $28: 72$ \\
\hline $\mathrm{CH}_{3}$ & $\mathrm{CH}_{3}$ & $\mathrm{CH}_{3}$ & 43 & 19 & $69: 31$ \\
\hline $\mathrm{CH}_{3}$ & $n-\mathrm{C}_{3} \mathrm{H}_{7}$ & $\mathrm{H}$ & 18 & 0 & $100: 0$ \\
\hline $\mathrm{CH}_{3}$ & $i-\mathrm{C}_{3} \mathrm{H}_{7}$ & $\mathrm{H}$ & 43 & 0 & $100: 0$ \\
\hline $\mathrm{C}_{2} \mathrm{H}_{5}$ & $\mathrm{H}$ & $\mathrm{H}$ & 0 & 59 & $0: 100$ \\
\hline $\mathrm{C}_{2} \mathrm{H}_{5}$ & $\mathrm{CH}_{3}$ & $\mathrm{H}$ & 0 & 37 & $0: 100$ \\
\hline $\mathrm{C}_{2} \mathrm{H}_{5}$ & $\mathrm{C}_{2} \mathrm{H}_{5}$ & $\mathrm{H}$ & 26 & 36 & $41: 59$ \\
\hline $\mathrm{C}_{2} \mathrm{H}_{5}$ & $\mathrm{CH}_{3}$ & $\mathrm{CH}_{3}$ & 32 & 13 & $71: 29$ \\
\hline $\mathrm{C}_{2} \mathrm{H}_{5}$ & $n-\mathrm{C}_{3} \mathrm{H}_{7}$ & $\mathrm{H}$ & 23 & 20 & $54: 46$ \\
\hline $\mathrm{C}_{2} \mathrm{H}_{5}$ & $i-\mathrm{C}_{3} \mathrm{H}_{7}$ & $\mathrm{H}$ & 44 & 0 & $100: 0$ \\
\hline $\mathrm{C}_{2} \mathrm{H}_{5}$ & $n-\mathrm{C}_{4} \mathrm{H}_{9}$ & $\mathrm{H}$ & 28 & 24 & $53: 47$ \\
\hline $\mathrm{C}_{2} \mathrm{H}_{5}$ & \multicolumn{2}{|c|}{$-\left(\mathrm{CH}_{2}\right)_{4^{-}}$} & 82 & 0 & $100: 0$ \\
\hline $\mathrm{C}_{6} \mathrm{H}_{5}$ & $\mathrm{H}$ & $\mathrm{H}$ & 0 & 40 & $0: 100$ \\
\hline $\mathrm{C}_{6} \mathrm{H}_{5}$ & $\mathrm{CH}_{3}$ & $\mathrm{H}$ & 14 & 31 & $31: 69$ \\
\hline $\mathrm{C}_{6} \mathrm{H}_{5}$ & $\mathrm{C}_{2} \mathrm{H}_{3}$ & $\mathrm{H}$ & 42 & 13 & $77: 23$ \\
\hline $\mathrm{C}_{6} \mathrm{H}_{5}$ & $\mathrm{CH}_{3}$ & $\mathrm{CH}_{8}$ & 68 & 15 & $82: 18$ \\
\hline $\mathrm{C}_{6} \mathrm{H}_{5}$ & $n-\mathrm{C}_{3} \mathrm{H}_{7}$ & $\mathrm{H}$ & 46 & 14 & $77: 23$ \\
\hline $\mathrm{C}_{6} \mathrm{H}_{5}$ & $i-\mathrm{C}_{8} \mathrm{H}_{7}$ & $\mathrm{H}$ & 62 & 0 & $100: 0$ \\
\hline $\mathrm{C}_{6} \mathrm{H}_{5}$ & $n-\mathrm{C}_{4} \mathrm{H}_{9}$ & $\mathrm{H}$ & 52 & 26 & $67: 33$ \\
\hline $\mathrm{C}_{6} \mathrm{H}_{5}$ & \multicolumn{2}{|c|}{$-\left(\mathrm{CH}_{2}\right)_{4}^{-}$} & 78 & 0 & $100: 0$ \\
\hline
\end{tabular}

種々の rーラクトンとビニルマグネシウムクロリドと の反応において，塩化銅 (I) が存在しない場合， $\alpha$ 位 の置換基が小さいと化合物 (3) 型のジオールが， $。$ 位の 置換基が大きいと化合物 (2) 型のケトン体が得られ, 塩 化銅 (I) 存在下では $\alpha$ 位の置換基の大小にかかわら ず化合物 (2) 型のケトン体が生成することを新たに知っ
Table 2 Reaction of $\gamma$-Lactones with Vinylmagnesium Chloride
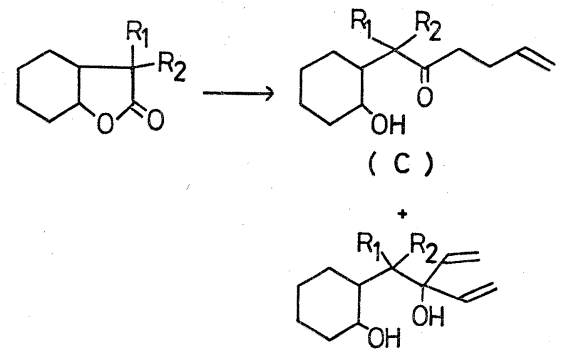

(D)

\begin{tabular}{l|c|rr|c}
\hline \multicolumn{2}{c|}{$\gamma$-Lactones } & \multicolumn{2}{c|}{ Products } & \multirow{2}{*}{$(\mathrm{C})$} \\
\multicolumn{1}{c|}{$\mathrm{R}_{1}$} & $\mathrm{R}_{2}$ & (yield, \%) & $(\mathrm{C}):(\mathrm{D})$ \\
\hline $\mathrm{H}^{*}$ & $\mathrm{H}$ & 0 & 0 & \\
$\mathrm{CH}_{3}$ & $\mathrm{H}$ & 0 & 50 & $0: 100$ \\
$\mathrm{C}_{2} \mathrm{H}_{5}$ & $\mathrm{H}$ & 22 & 43 & $34: 66$ \\
$\mathrm{CH}_{3}$ & $\mathrm{CH}_{3}$ & 63 & 0 & $100: 0$ \\
$n-\mathrm{C}_{3} \mathrm{H}_{7}$ & $\mathrm{H}$ & 48 & 0 & $100: 0$ \\
$i-\mathrm{C}_{3} \mathrm{H}_{7}$ & $\mathrm{H}$ & 32 & 0 & $100: 0$ \\
$n-\mathrm{C}_{4} \mathrm{H}_{9}$ & $\mathrm{H}$ & 56 & 13 & $82: 18$ \\
\multicolumn{2}{c}{$-\left(\mathrm{CH}_{2}\right)_{4}-$} & 76 & 0 & $100: 0$ \\
\hline In this case, 6,6-divinyl-5-oxabicyclo〔4.3.0] nonane was
\end{tabular}
obtained in $32 \%$ yield.

Table 3 Reaction of $\gamma$-Lactones with Vinylmagnesium Chloride in the presence of Copper ( I ) Chloride<smiles>[R]C(O)CC([R2])([R3])C(=O)CCC=C</smiles>

(A)

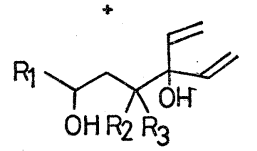

(B)

\begin{tabular}{|c|c|c|c|c|c|}
\hline \multicolumn{3}{|c|}{$\gamma$-Lactones } & \multirow{2}{*}{\multicolumn{2}{|c|}{$\begin{array}{l}\text { Products } \\
\text { (A) (B) } \\
\text { (yield, \%) }\end{array}$}} & \multirow{2}{*}{$(A):(B)$} \\
\hline $\mathrm{R}_{1}$ & $\mathrm{R}_{2}$ & $\mathrm{R}_{3}$ & & & \\
\hline $\mathrm{CH}_{3}$ & $\mathrm{H}$ & $\mathrm{H}$ & 33 & 0 & $100: 0$ \\
\hline $\mathrm{CH}_{3}$ & $\mathrm{CH}_{3}$ & $\mathrm{H}$ & 40 & 3 & $94: 6$ \\
\hline $\mathrm{CH}_{3}$ & $\mathrm{C}_{2} \mathrm{H}_{5}$ & $\mathrm{H}$ & 54 & 3 & $94: 6$ \\
\hline $\mathrm{CH}_{8}$ & $\mathrm{CH}_{3}$ & $\mathrm{CH}_{3}$ & 42 & 0 & $100: 0$ \\
\hline $\mathrm{CH}_{3}$ & $n \mathrm{C}_{3} \mathrm{H}_{7}$ & II & 77 & 0 & $100: 0$ \\
\hline $\mathrm{CH}_{3}$ & $i-\mathrm{C}_{3} \mathrm{H}_{7}$ & $\mathrm{H}$ & 52 & 0 & $100: 0$ \\
\hline $\mathrm{C}_{2} \mathrm{H}_{5}$ & $\mathrm{H}$ & $\mathrm{H}$ & 67 & 2 & $98: 2$ \\
\hline $\mathrm{C}_{2} \mathrm{H}_{5}$ & $\mathrm{CH}_{3}$ & $\mathrm{H}$ & 34 & 3 & $93: 7$ \\
\hline $\mathrm{C}_{2} \mathrm{H}_{5}$ & $\mathrm{C}_{2} \mathrm{H}_{5}$ & $\mathrm{H}$ & 67 & 0 & $100: 0$ \\
\hline $\mathrm{C}_{2} \mathrm{H}_{5}$ & $\mathrm{CH}_{3}$ & $\mathrm{CH}_{3}$ & 29 & 0 & $100: 0$ \\
\hline $\mathrm{C}_{2} \mathrm{H}_{5}$ & $n-\mathrm{C}_{3} \mathrm{H}_{7}$ & $\mathrm{H}$ & 66 & 0 & $100: 0$ \\
\hline $\mathrm{C}_{2} \mathrm{H}_{5}$ & $i-\mathrm{C}_{8} \mathrm{H}_{7}$ & $\mathrm{H}$ & 72 & 0 & $100: 0$ \\
\hline
\end{tabular}


た。またこれらの反応で得られる化合物 (2) 型のケト ン体および化合物 (3) 型のジオール体は, 有機合成反応 の中間体として利用できると考えられる。

\section{3. 実験}

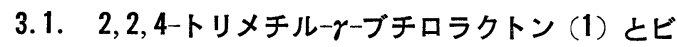
ニルマグネシウムクロリドの反応乾燥窒素気流中 $0^{\circ} \mathrm{C}$ に保った 2,2,4-トリメチルーr-ブチロラクトン (1) 0.05 モル (6.4 g) の THF $60 \mathrm{ml}$ 溶液に 0.3 モル相当 のビニルマグネシウムクロリドの THF 溶液 $150 \mathrm{ml}$ を 1 時間かけて滴下した。反応混合物を除々に温度を上げ 8 時間還流した。室温まで泠却した後, 飽和塩化アンモ ニウム水溶液で加水分解した。イソプロピルエーテルで 抽出しエーテル溶液は水洗後, 無水硫酸ナトリウムで乾 燥した。エーテルを留去後減圧蒸留して, 化合物 (2) は 最初に得られる bp $80 \sim 92^{\circ} \mathrm{C}(5 \mathrm{mmHg})$ (収量 $1.2 \mathrm{~g}$ ) の留分の再蒸留により単離し IR, NMR スペクトルによ りその構造を確認した。化合物 (3) は後に得られる bp $110 \sim 125^{\circ} \mathrm{C}$ (5 mmHg) (収量 $3.6 \mathrm{~g}$ ) の留分のシリカゲ ルを用いるカラムクロマトグラフィーを行なうことによ り $n$ 一ヘキサン・酢酸エチル $(7: 3)$ 溶出液から単離し IR, NMR スペクトルによりその構造を確認した。

化合物 (2) : IR (液膜) : $3450(\mathrm{OH}), 1695(\mathrm{C}=\mathrm{O})$, $1640,990,910 \mathrm{~cm}^{-1}$ (末端ビニル); $\operatorname{NMR}\left(\mathrm{CCl}_{4}\right): \delta 0.95$ $\left(\mathrm{s}, 3 \mathrm{H}, \mathrm{CH}_{3}\right), 1.05\left(\mathrm{~s}, 3 \mathrm{H}, \mathrm{CH}_{3}\right), 1.1(\mathrm{~d}, \mathrm{~J}=6 \mathrm{~Hz}$, $\left.3 \mathrm{H}, \mathrm{CH}_{3} \mathrm{CH}\right), 1.2 \sim 2.4\left(\mathrm{~m}, 6 \mathrm{H},-\mathrm{CH}_{2}-\times 3\right), 2.7(\mathrm{~s}$, $1 \mathrm{H}, \mathrm{OH}), 4.0(\mathrm{~m}, 1 \mathrm{H}, \mathrm{CHOH}), 5.0(\mathrm{~m}, 2 \mathrm{H},-\mathrm{CH}=$ $\left.\mathrm{CH}_{2}\right), 5.8\left(\mathrm{~m}, 1 \mathrm{H},-\mathrm{CH}=\mathrm{CH}_{2}\right)$ 。

化合物 (3) : IR (液膜) : $3300(\mathrm{OH}), 1640,990,910$ $\mathrm{cm}^{-1}$ (末端ビニル);NMR $\left(\mathrm{CCl}_{4}\right): \delta 0.8\left(\mathrm{~s}, 3 \underline{\mathrm{H}}, \mathrm{CH}_{3}\right)$, $0.9\left(\mathrm{~s}, 3 \mathrm{H}, \mathrm{CH}_{3}\right), 1.0\left(\mathrm{~d}, \mathrm{~J}=6 \mathrm{~Hz}, \mathrm{CH}_{3} \mathrm{CH}\right), 1.7$ (d, $\left.\mathrm{J}=6 \mathrm{~Hz}, 2 \mathrm{H},-\mathrm{CH}-\mathrm{CH}_{2}-\right), 3.7(\mathrm{~m}, 1 \mathrm{H},-\mathrm{CH} \mathrm{OH})$, $4.8(\mathrm{~s}, 2 \mathrm{H},-\mathrm{OH} \times 2), 5.1\left(\mathrm{~m}, 4 \mathrm{H},-\mathrm{CH}=\mathrm{CH}_{2} \times 2\right)$, $5.8\left(\mathrm{~m}, 2 \mathrm{H},-\mathrm{CH}=\mathrm{CH}_{2}\right)$ 。

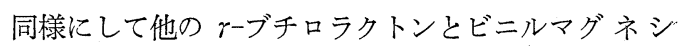
ウムクロリドとの反応を試み，その結果を表 1 , 表 2 に 示した。塩化銅 (I) 存在下での反応も同様にして試み 結果を表 3 に示した。

\section{文献}

1) H. Normant, "Advances in Organic Chemistry, Method and Results," II, Interscience, New York, 1960, p. 1

2) K. Suga, S. Watanabe, T. Fujita Y. Takahashi, Aust. J. Chem., 26, 2123 (1973)

3）須賀恭一，渡辺昭次，藤田力，吉田幸司，有合 化, 34, 661 (1976)

4) J. Colonge, R. Marey, Org. Synth. IV, 1963, p. 601

5) S. Watanabe, K. Suga, T. Fujita, Y. Takahashi, Can. J. Chem., 50, 2786 (1972)

\section{油脂製品の知識}

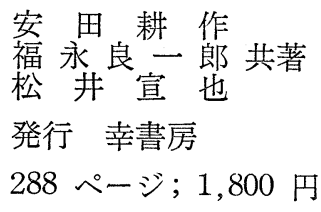

1. 油脂の種類と性質， 2 . 油脂の製造，3.油脂製品，を 3 人の分筆によっている。参考文献などを見ても，最 近の油脂化学は比較的進歩の少ない分野のようであるが，1,6，の油脂の栄養における必須脂肪酸の意義や，2,3,4. の油脂分別法の連続式パーム油分別装置などは比較的新しい資料が用いられている。3,1,6,の食用油についての疑 問についてはもう少し科学的な解答がほしかった。

(Y.H.) 